\title{
The effects of blood pressure and the renin-angiotensin-aldosterone system on regional cerebral blood flow and cognitive impairment in dialysis patients
}

\begin{abstract}
Shuzo Kobayashi, Yasuhiro Mochida, Kunihiro Ishioka, Machiko Oka, Kyouko Maesato, Hidekazu Moriya, Sumi Hidaka and Takayasu Ohtake

Cognitive dysfunction is prevalent in chronic kidney disease patients. Little is known about the relationship between the regional cerebral blood flow (rCBF) and cognitive function in hemodialysis (HD) patients. We used quantitative single-photon emission-computed tomography (SPECT) to determine whether rCBF decreased in these patients. Fifty-four consecutive HD patients who were able to visit the hospital unassisted and had no history of stroke underwent cognitive assessment based on the Mini Mental State Examination (MMSE). Using quantitative image-analysis software, the SPECT imaging data were used to compare rCBF in HD patients and age-matched healthy controls. Thirty-four patients $(63 \%)$ had MMSE scores $\geqslant 28$ (nondementia). Regarding the extent of decreased rCBF in HD patients compared with rCBF in normal control patients, SPECT demonstrated significant $\mathrm{rCBF}$ decreases in all patients. rCBF in the perfusion area of the middle cerebral artery was significantly more decreased than in other areas. Multiple logistic regression analysis demonstrated that the presence or absence of a previous history of percutaneous coronary intervention, drug therapy with angiotensin II receptor antagonists and diastolic blood pressure (DBP) were independent risk factors for the extent of decreased rCBF. Regarding the severity of decreased $\mathrm{rCBF}$, stepwise multiple regression analysis indicated that HD duration and systolic blood pressure $(\mathrm{mm} \mathrm{Hg})$ were chosen. In conclusion, rCBF decreased in all HD patients studied, irrespective of their clinical symptoms or MMSE scores. Blood pressure was an independent risk factor affecting the extent of decreased rCBF.
\end{abstract} Hypertension Research (2014) 37, 636-641; doi:10.1038/hr.2014.57; published online 3 April 2014

Keywords: blood pressure; cerebral blood flow; cognitive impairment; hemodialysis; renin-angiotensin system

\section{INTRODUCTION}

It has been reported that silent brain infarcts have an increased risk of dementia and a steeper decline in cognitive function. ${ }^{1}$ We have already reported that asymptomatic cerebral lacunar infarcts are more prevalent in chronic kidney disease (CKD) patients. ${ }^{2}$ It has been demonstrated that CKD and lacunar infarcts are associated with cognitive impairment. ${ }^{3}$ However, little is known about the relationship between regional cerebral blood flow $(\mathrm{rCBF})$ and cognitive function.

Cognitive impairment is an important problem to solve because of the staggering financial and social tolls on patients and their families. It has long been recognized as a complication in dialysis patients. ${ }^{4}$ Recent studies have indicated that cognitive impairment is present in the early stages of CKD, and the prevalence is greater among patients with lower eGFRs, independent of the traditional vascular risk factors that may be explained by anemia., ${ }^{5,6}$ In addition, impaired kidney function is associated with a more rapid rate of cognitive decline in old age. ${ }^{7}$ The prevalence of moderate-to-severe cognitive impairment in hemodialysis (HD) patients is more than double that in the general population; up to $70 \%$ of HD patients are 55 years old and older, have moderate-to-severe cognitive impairment. ${ }^{8}$ In peritoneal dialysis patients, the same evidence has been demonstrated. ${ }^{9}$

It has been reported that cardiovascular risk factors promote brain hypoperfusion, leading to cognitive decline and dementia, ${ }^{10}$ and high blood pressure is associated with faster cognitive decline in mild cognitive impairment (MCI). ${ }^{11,12}$ Therefore, in dialysis patients, it is important to study cerebral blood flow and its associated factors.

Recently, several types of drugs acting as central cholinergic stimulants ${ }^{13}$ have been reported to have a favorable effect on the improvement of clinical symptoms and rCBF. Better effects can be obtained with earlier diagnoses. ${ }^{14}$ Therefore, it is important to diagnose cognitive impairment pre-clinically at an early stage before 
the disease becomes clinically evident. Thus, MCI, regardless of whether it is Alzheimer's disease (AD) or non-Alzheimer's dementia, such as vascular dementia, garners much attention because it may be possible to improve the cognitive impairment with drug therapy. Indeed, it has been recently shown that Donepezil improves cognitive dysfunction in patients with vascular dementia. ${ }^{15}$

Excellent progress in nuclear medicine has allowed the early detection of abnormal cerebral blood flow changes. Various imaging procedures and techniques, such as conventional magnetic resonance imaging, neuroimaging using single-photon emission-computed tomography (SPECT) and positron emission tomography, have been used as objective diagnostic methods. In particular, advanced statistical brain imaging analysis using SPECT three-dimensional stereotactic surface projections (3D-SSPs) can demonstrate regional brain hypoperfusion. ${ }^{16}$ With this technique, it is possible to quantify $\mathrm{rCBF}\left(\mathrm{ml}\right.$ per $100 \mathrm{~g} \mathrm{~min}^{-1}$ ) in every gyrus. Because of limitations in the ability to quantitatively assess the extent of lesions, Mizumura et al. developed the stereotactic extraction estimation (SEE) method, which can identify orientation and increased reduction by classifying stereotactic brain coordinates according to the anatomic structure. ${ }^{17}$

Using these modern tools, we assessed whether HD patients without previous histories of stroke or clinically evident dementia have reduced $\mathrm{rCBF}$.

\section{METHODS}

\section{Patients}

Sixty-one consecutive HD patients in our hospital provided informed consent to undergo SPECT and were included in the present study. Seven of the sixtyone patients were excluded because they had previous histories of stroke. All patients could walk and visit our hospital unassisted and were independent of the caregivers in terms of their activities of daily living. The underlying causes of CKD in the 54 patients who were included in the study were glomerulonephritis $(n=24)$, diabetes mellitus $(n=19)$ and others or unknown $(n=11)$. All patients had undergone HD for at least 3 months, and the mean duration of HD was 112 months. The study was performed in compliance with the Declaration of Helsinki.

\section{Cognitive assessment}

The cognitive assessment was based on the Mini Mental State Examination (MMSE). ${ }^{18}$ As the standard MMSE cut score of 24 has been widely used, we diagnosed cognitive impairment if the MMSE score was $\leqslant 24 .{ }^{19}$ Moreover, as a cutoff score of 27 was proposed for MCI, we diagnosed MCI if the MMSE score was between 25 and $27 .{ }^{20}$ We considered an MMSE score $\geqslant 28$ to indicate non-dementia.

\section{${ }^{123}$ I-IMP brain SPECT studies}

We collected SPECT data (continuous mode, 36 views, $35 \mathrm{~s}^{-1}$ view) for approximately $30 \mathrm{~min}$ after the intravenously injecting the subjects with $185 \mathrm{MBq}(5 \mathrm{mCi}){ }^{123} \mathrm{I}$-IMP (iodoamphetamine); the subjects were at rest in the supine position with their eyes closed. The matrix size was $64 \times 64$, and the collection window was $159 \mathrm{keV}$ at $20 \%$. For pre-filter and absorption correction, the Ramp-Butterworth filter (order 5, cutoff 0.26) and the Radial post-correction methods were used, and images were reconstructed using the back-projection method. The image voxel size was $2 \times 2 \times 5 \mathrm{~mm}^{3}$. The SPECT system used had a ring-type gamma camera (dual-head rotating gamma camera, E.CAM, Siemens Medical Solutions, New York, NY, USA) with a lowenergy high-resolution collimator permitting a spatial resolution of $6.62 \mathrm{~mm}$, full width at half maximum. Imaging began $15 \mathrm{~min}$ after an intravenous injection of $185 \mathrm{MBq}$.

Data analysis

The data obtained from the ${ }^{123}$ I-IMP SPECT images were analyzed with Neurostat/3D-SSP image-analysis software (iSSP version 3.5, Mediphysics,
Tokyo, Japan), ${ }^{16,21}$ which was developed by Minoshima et al. The data were normalized to the mean global activity. We then applied the analysis software SEE developed by Mizumura et al. ${ }^{17}$ We divided the whole brain into segments according to the SEE methods (arterial blood supply level classification, lobe level classification and gyrus level classification) using the Talairach brain atlas. ${ }^{22}$ The arterial blood supply level corresponds to the anterior, middle and posterior cerebral arteries (ACA, MCA and PCA, respectively).

\section{Table 1 Basic characteristic of 54 patients who were studied}

\begin{tabular}{lc}
\hline Male/female & $33 / 21$ \\
Age (years) & $67.8 \pm 11.3$ \\
HD duration (months) & $112 \pm 11.3$ \\
Smoker & 18 \\
DM & 19 \\
PCI & 9 \\
CABG & 0 \\
VD3 & 39 \\
ARB & 33 \\
SBP mm Hg & $142 \pm 18$ \\
DBP mm Hg & $75 \pm 13$ \\
MMSE & $28(9 \sim 30)$
\end{tabular}

Abbreviations: ARB, angiotensin II receptor antagonist; DBP, diastolic blood pressure; DM, diabetes mellitus; HD, hemodialysis; MMSE, Mini Mental State Examination; PCI, percutaneous coronary intervention; SBP, systolic blood pressure; VD3, 1,25 (OH)2 vitamin D3. MMSE is shown in median (minimum-maximum).

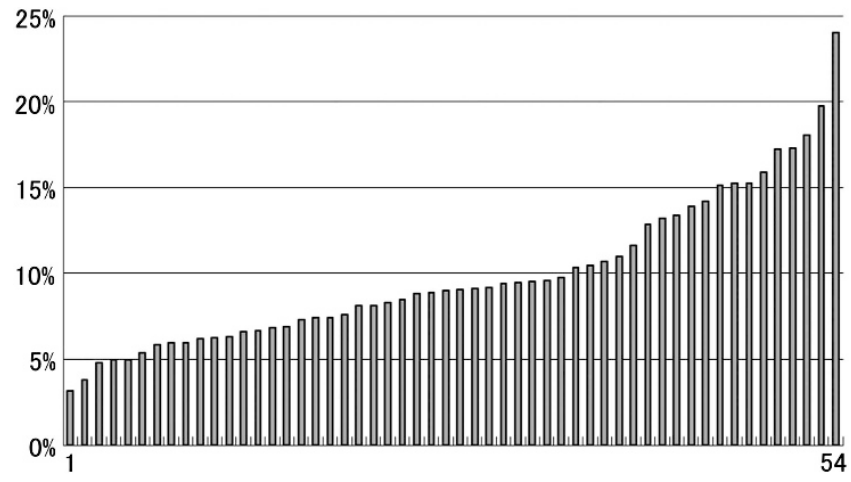

Figure 1 The maximum extent of decreased regional cerebral blood flow (rCBF) by $Z$-score of $>2$ in each patient is ranked. The extent is expressed as the rate of the total coordinates with a significantly reduced $Z$-score in the vascular territory areas (anterior, middle and posterior cerebral arteries; extent). A Z-score $>2$ was defined as decreased $\mathrm{rCBF}$, which corresponds to a decrease of $>2$ s.d. of the average values compared with the reference values.

Table 2 Maximum vascular territory ratio (\%) in the decreased rCBF of the ACA, MCA and PCA perfusion areas

\begin{tabular}{lrrrrrr}
\hline & Left ACA & Right ACA & Left MCA & Right MCA & Left PCA & Right PCA \\
\hline Mean & 9.0 & 9.1 & 12.0 & 12.0 & 6.0 & 7.3 \\
s.d. & 8.4 & 7.9 & 6.9 & 7.1 & 9.1 & 10.9 \\
Median & 5.2 & 8.0 & 12.0 & 11.3 & 2.0 & 3.2 \\
Minimum & 0.3 & 0.0 & 0.2 & 1.3 & 0.0 & 0.0 \\
Maximum & 31.5 & 36.4 & 41.3 & 27.7 & 45.0 & 51.7
\end{tabular}

Abbreviations: ACA, anterior cerebral artery; MCA, middle cerebral artery; PCA, posterior cerebral artery; $\mathrm{rCBF}$, regional cerebral blood flow.

The left and right MCA territory areas showed significant decreases in $\mathrm{rCBF}$, compared with that The left and right MCA territory areas showed significant decreases in rCBF, compared
in the ACA and PCA territory areas by analysis of variance (Tukey's honestly significant difference). 
We prepared a reference table in which the obtained brain coordinates corresponded to anatomical information, and we obtained the $Z$-score, which corresponds to the standard deviation (s.d.) of the average values obtained from healthy volunteers aged between 52 and 78 years old $(\mathrm{M} / \mathrm{F}=10: 19$, $64.2 \pm 8.2, \mathrm{MMSE} \geqslant 28)^{23}$ and to the association between the coordinates in the prepared reference table and the case coordinates. We then calculated the total coordinate data with a $Z$-score set as a significant finding. Extent was defined as the percentage of the area in which rCBF decreased by more than two s.d. of the normal references in the respective segments, and severity was defined as the values of the s.d. themselves ( $Z$-score). A $Z$-score $>2$ was defined as decreased rCBF. We prepared a table by combining the indices according to segments and anatomical classification, and we assessed any significant decreases in accumulation (SEE method).

\section{Statistical analysis}

The continuous variables were expressed as the means \pm s.d. and were compared using analysis of variance followed by Tukey's honestly significant difference test. We evaluated the distribution of the MMSE scores. Using SEE methods, we studied two parameters: the severity and extent of rCBF. Univariate or multivariate logistic analyses were performed between the territory ratio in each blood supply area showing decreased rCBF with a $Z$-score $>2$ and various parameters, including age, HD duration, various types of drug usage (anti-hypertensive medication, vitamin D3), smoking habit, history of percutaneous coronary intervention (PCI), blood pressure, MMSE score, hemoglobin level, as well as the serum levels of high sensitive CRP (hsCRP), albumin, blood urea nitrogen and $\beta 2$-microglobulin.

To perform the logistic analysis, decreased $\mathrm{rCBF}$ was defined as the presence or absence of more than the 75th percentile in the territory area (ACA, MCA and PCA) when the percentage of the territory area showing decreased rCBF with a $Z$-score $>2$ was ranked for all patients. Decreased rCBF was used as a dependent variable. Regarding severity, using the extent of the s.d. decrease in the gyrus level classification, univariate regression analysis was performed to show the associated factors. Then, to obtain an equation to predict the maximum severity in decreased rCBF, stepwise multiple regression analysis was performed. A $P$-value $>0.05$ was considered statistically significant

\section{RESULTS}

\section{Subject characteristics}

The mean age and HD duration were $67.8 \pm 11.3$ years and $112 \pm 132$ months (median 80, 3 845 months), respectively (Table 1). The study cohort included 19 patients with diabetes mellitus and 9 patients with a history of PCI. The mean SBP and DBP $(\mathrm{mm} \mathrm{Hg})$ were $142 \pm 18$ and $75 \pm 13$, respectively. Angiotensin II receptor antagonists (12 valsartan, 8 telmisartan, 3 losartan and 16 olmesartan) were used in 39 patients, and vitamin $\mathrm{D}_{3}$ was used in 33 patients. All patients underwent HD treatments three times weekly, $12 \mathrm{~h}$ per week. The $\mathrm{Kt} / \mathrm{V}$ urea was $1.38 \pm 0.16$. Either a polysulfone $(n=16)$ or a triacetate membrane $(n=28)$ was used for dialysis.

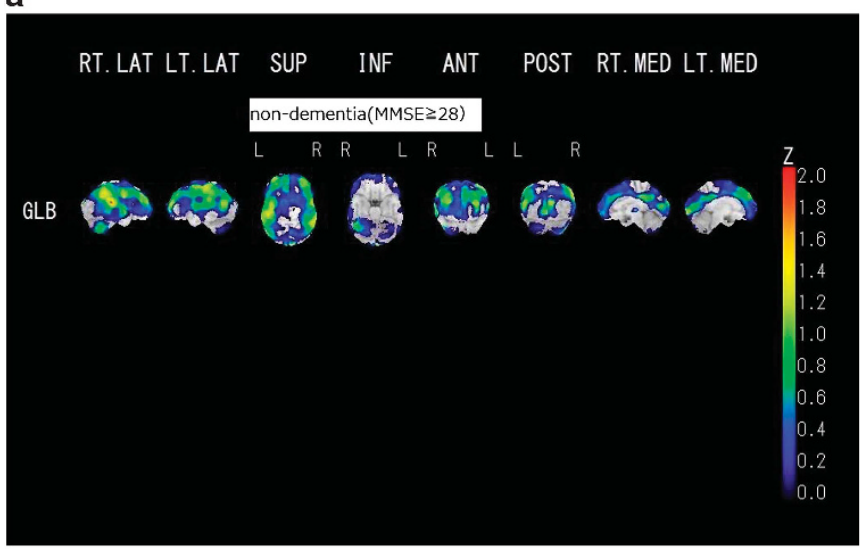

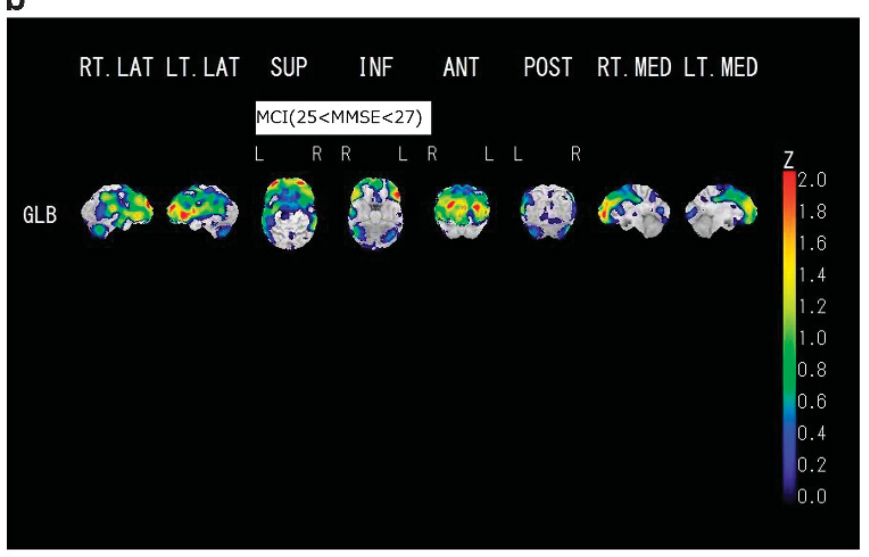

C

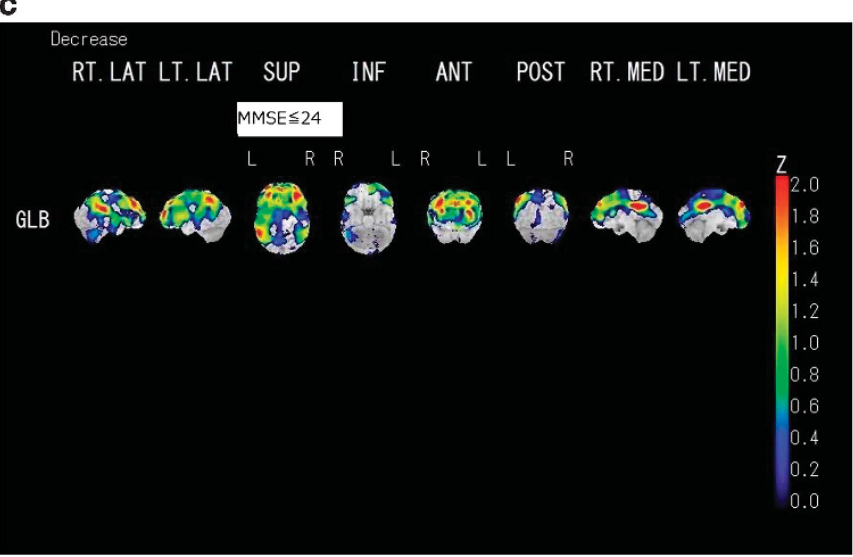

Figure 2 Representative changes in regional cerebral blood flow (rCBF) are shown based on the Talairach brain atlas. ${ }^{15}$ The Z-score is shown in the right column from blue to red in order of decreasing rCBF. (a) The summation pattern of rCBF obtained from patients (non-dementia) with Mini Mental State Examination (MMSE) scores $\geqslant 28$ is shown. (b) The summation pattern of rCBF obtained from patients (mild cognitive impairment) with MMSE scores ranging from 25 to 27 is shown. (c) The summation pattern of rCBF obtained from patients (dementia) with MMSE scores $\leqslant 24$ is shown. The frontal lobe, temporoparietal lobe and cingulate gyrus show decreased rCBF. GLB, averaged global activity. A full color version of this figure is available at the Hypertension Research journal online. 


\section{MMSE}

The mean MMSE score was 28 (minimum/maximum, 9/30). A total of 34 patients $(63 \%)$ had MMSE scores $\geqslant 28$ (non-dementia), and 13 patients (24\%) had MMSE scores of 25-27, which corresponded to MCI. Seven patients $(13 \%)$ had MMSE scores $\leqslant 24$.

\section{SPECT}

For each patient, the maximum percentage area of decreased $\mathrm{rCBF}$ in the territory of three (ACA, MCA and PCA) artery perfusion areas is shown in Figure 1. Regarding the extent of the decreased $\operatorname{rCBF}(>2$ s.d.), all patients showed significant decreases in $\mathrm{rCBF}$ (Figure 1), irrespective of MMSE scores. $\mathrm{rCBF}$ in the perfusion area of the middle cerebral artery was significantly decreased compared with other areas, as shown in Table 2 . The total rCBF reduction pattern ( $>2$ of the $Z$-score) of all patients is shown in Figure 2. The figures are based on the representative summation patterns of normal (Figure $2 a$ ) patients with MCI (Figure 2b) and dementia (Figure 2c), respectively. The frontal lobe, temporoparietal lobe and cingulate gyrus more clearly show decreased rCBF. rCBF is expressed as $\mathrm{ml}$ per $100 \mathrm{~g} \mathrm{~min}^{-1}$ in each area (Figure 3). rCBF decreased in the cingulate and parahippocampus gyrus. As shown in Table 3, when the presence of decreased $\mathrm{rCBF}$ was defined as a dependent variable, the usage of angiotensin II receptor antagonist $(r=-0.308, P=0.023)$, DBP $(r=0.281, P=0.039)$ and history of PCI $(r=0.302, P=0.026)$ were significantly associated with decreased $\mathrm{rCBF}$. When a 75th-percentile decrease in $\mathrm{CCBF}$ of the vascular territory ratio (ACA, MCA and PCA) was defined as the presence of decreased $\mathrm{rCBF}$, multivariate logistic analysis (including variables with $P$ values $<0.20$ ) showed that the use of angiotensin II receptor antagonist (odds ratio, 0.183; 95\% confidence interval, 0.039-0.849), DBP (odds ratio, 1.060; 95\% confidence interval, 1.000-1.123) and history of PCI (odds ratio, 9.911; 95\% confidence interval, 1.491-65.867) were independent risk factors for the extent of the decreased rCBF (Table 4).
When we studied the correlation between MMSE and decreased $\mathrm{rCBF}$ as a 'percentage vs extent' ratio, $\mathrm{rCBF}$ in the cingulate gyrus and frontal lobe had a significant negative correlation with MMSE scores, as shown in Table 5. However, irrespective of the MMSE scores, all patients again showed a significant decrease in the severity of rCBF, with a $Z$-score $>2$, thus $3.54 \pm 0.81$ (median, 3.32; minimummaximum, 2.60-6.57). Moreover, there were positive correlations with age, HD duration, SBP, DBP and serum C-reactive protein and $\beta 2$-microglobulin levels, as shown in Table 6. Stepwise multiple regression analysis revealed that $\mathrm{HD}$ duration (months) and SBP $(\mathrm{mmHg})$ were independent contribution factors as determinants of the maximum severity of the decreased $\mathrm{rCBF}$, as follows: maximum severity of decreased $\mathrm{rCBF}=0.002 \times \mathrm{HD}$ duration (months) +0.016 $\mathrm{SBP}(\mathrm{mm} \mathrm{Hg})+0.221\left(R=0.501, R^{2}=0.224, P=0.0003\right)$.

\section{DISCUSSION}

We demonstrated that all HD patients studied in the present study had a significantly decreased rCBF. Even if the patients appeared to have normal cognitive function, they had decreased $\mathrm{rCBF}$, which is an important clinical issue because clinically evident dementia may develop in the future. At present, the precise meaning of these results is still unknown. However, the results might suggest the findings that CKD patients have more prevalent ischemic brain infarcts irrespective of symptoms and the risk of dementia $(1,2,3)$.

Concerning the MMSE score, 63\% of HD patients had normal MMSE scores and $24 \%$ of the patients had MCI. Patients with clearly decreased MMSE scores < 24 (13\% of all patients) must be carefully followed because there is the possibility that they may develop dementia.

In the present study, most of the patients had normal cognitive function. In $\mathrm{AD}$ patients, it is known that energy metabolism is reduced in the posterior cingulate cortex, although the cause of the abnormal energy metabolism in the posterior cingulate circuit and its

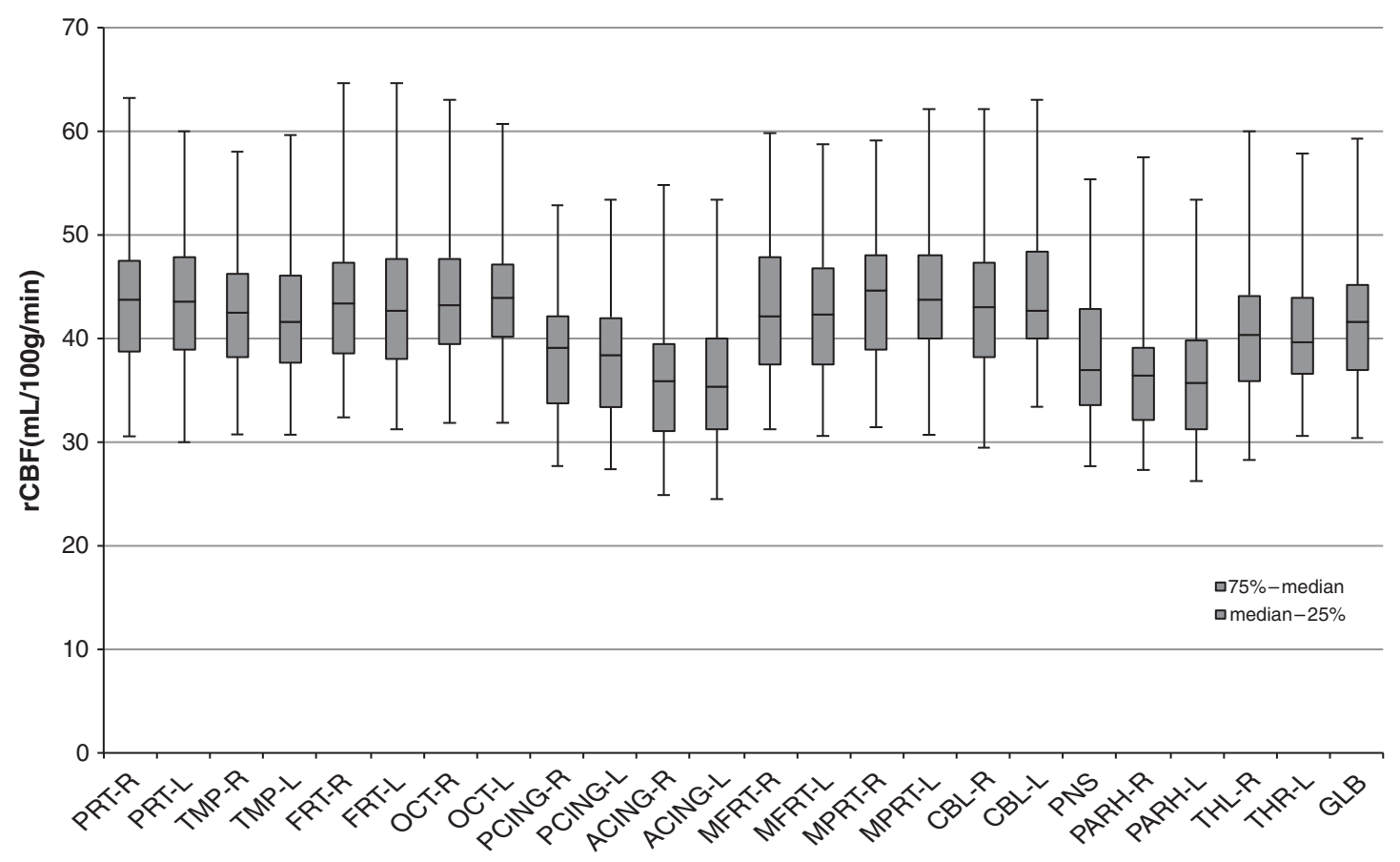

Figure 3 Regional cerebral blood flow (rCBF) in each area is shown as ml per $100 \mathrm{gmin}^{-1}$. ACING, anterior cingulate cortex; CBL, cerebellar hemisphere; FRT, frontal association cortex; GLB, averaged global activity; MFRT, medial frontal cortex; MPRT, medial parietal cortex; OCT, occipital association cortex; PARH, para-hippocampus gyrus; PCING, posterior cingulate cortex; PNS, Pons; PRT, parietal association cortex; THL, thalamus; TMP, temporal association cortex. 
Table 3 Univariate associations with the extent of decreased $\mathrm{rCBF}$ in the vascular territory (ACA, MCA, PCA) ratio

\begin{tabular}{|c|c|c|}
\hline & $r$ & P-value \\
\hline Age & 0.096 & 0.491 \\
\hline Sex & 0.046 & 0.726 \\
\hline HD duration & -0.088 & 0.525 \\
\hline VD3 & 0.064 & 0.547 \\
\hline ARB & -0.308 & 0.023 \\
\hline Smoker & 0.030 & 0.830 \\
\hline DM & 0.184 & 0.184 \\
\hline $\mathrm{PCl}$ & 0.302 & 0.026 \\
\hline MMSE & -0.234 & 0.089 \\
\hline SBP & 0.179 & 0.216 \\
\hline DBP & 0.281 & 0.039 \\
\hline $\mathrm{Hb}$ & -0.064 & 0.647 \\
\hline BUN & -0.094 & 0.501 \\
\hline $\mathrm{Cr}$ & -0.133 & 0.338 \\
\hline CRP & 0.131 & 0.344 \\
\hline Albumin & -0.169 & 0.221 \\
\hline$\beta 2 \mathrm{MG}$ & 0.079 & 0.571 \\
\hline
\end{tabular}

Table 4 Multiple logistic regression analysis when a 75th-percentile decrease in the rCBF of the vascular territory ratio (ACA, MCA and PCA) was defined as the presence of decreased $\mathrm{rCBF}$, showed usage of a RAS inhibitor and the presence of a previous history of $\mathrm{PCl}$ as independent factors contributing to the extent of decreased rCBF

\begin{tabular}{lrrrr}
\hline & B & P-value & Exp (B) & 95\% Cl lower-upper \\
\hline ARB & -1.698 & 0.030 & 0.183 & $0.039-0.849$ \\
PCI & 2.294 & 0.018 & 9.911 & $1.491-65.867$ \\
DBP & 0.058 & 0.048 & 1.060 & $1.000-1.123$ \\
\hline
\end{tabular}

Abbreviations: ARB, angiotensin II receptor antagonist; ACA, MCA, PCA, anterior, middle, and posterior cerebral artery, respectively; $\mathrm{Cl}$, confidence interval; DBP, diastolic blood pressure;

$\mathrm{PCl}$, percutaneous coronary intervention; rCBF, regional cerebral blood flow.

functional significance in cognitive dysfunctions in $\mathrm{AD}$ require further investigation. ${ }^{24}$ It is also known that temporoparietal hypoperfusion, including the posterior cingulate on SPECT brain imaging, is useful for diagnosing $\mathrm{AD} .^{25}$ The present study of HD patients demonstrated that decreased $\mathrm{rCBF}$ is found not only in these areas but also in other areas. Indeed, $\mathrm{rCBF}$ in the MCA territory area was significantly decreased compared with that in the ACA and PCA territory areas. The fact that asymptomatic lacunae infarction is more prevalent in $\mathrm{CKD}$, as we have already reported, ${ }^{2}$ may explain this finding. Small vessel disease found in CKD is an abnormality of the penetrating arteries that branch from the MCA in white matter. ${ }^{3}$

Associated factors related to decreased $\mathrm{rCBF}$ are the presence or absence of a previous history of PCI and angiotensin II receptor antagonist medication. In an animal study, it was shown that angiotensin II type 2 receptor stimulation has a protective effect on ischemic brain lesions, at least partly through the modulation of cerebral blood flow. ${ }^{26}$ Moreover, it has been reported that the reninangiotensin system has a pivotal role in cognitive impairment, and the renin-angiotensin system blockade is a notable strategy for preventing
Table 5 Correlations between MMSE and rCBF in each territory expressed as \% extent ratio are shown

\begin{tabular}{lccccccc}
\hline & Mean & MIN & MAX & s.d. & Median & r & P-value \\
\hline MMSE & 27.2 & 9 & 30 & 3.7 & 28 & & \\
Precuneus L & 5.7 & 0 & 48.1 & 10.3 & 0.0075 & -0.215 & NS \\
Precuneus R & 10.9 & 0 & 54.3 & 15.9 & 0.024 & 0.008 & NS \\
Cingulate gyrus L & 10.2 & 0 & 48.4 & 11.9 & 0.062 & -0.23 & NS \\
Cingulate gyrus R & 11.4 & 0 & 54.7 & 12.1 & 0.089 & -0.282 & $<0.05$ \\
Anterior cingulate L & 5 & 0 & 45 & 10.9 & 0.003 & -0.145 & NS \\
Anterior cingulate R & 4.9 & 0 & 37.8 & 10 & 0.0085 & -0.154 & NS \\
Posterior cingulat L & 7.3 & 0 & 50.9 & 11.4 & 0.025 & -0.149 & NS \\
Posterior cingulat R & 9.2 & 0 & 53.6 & 13.9 & 0.009 & -0.155 & NS \\
Frontal lobe_L & 11.4 & 0.4 & 34.5 & 9 & 0.089 & -0.288 & $<0.05$ \\
Frontal lobe_R & 11.3 & 0 & 38.6 & 8.6 & 8.6 & -0.352 & $<0.05$ \\
Temporal lobe_L & 7.7 & 0 & 24.6 & 6.8 & 0.054 & 0.104 & NS \\
Temporal lobe_R & 7.1 & 0 & 22.9 & 5.2 & 0.0675 & 0.103 & NS \\
\hline
\end{tabular}

Abbreviations: MAX, maximum; MIN, minimum; MMSE, Mini Mental State Examination; NS, not significant; $r C B F$, regional cerebral blood flow.

The $\mathrm{rCBF}$ in cingulate gyrus and frontal lobe is negatively correlated with MMSE. Extent ratio was defined as the percentage of the area in which rCBF decreased more than 2 s.d. of normal references in the respective segments. Figures except MMSE are shown as \% of area in each territory.

Table 6 All patients, irrespective of MMSE score, showed a significant decrease in $\mathrm{rCBF}$ and severity was a Z-score of more than 2, namely, 3.54 \pm 0.81 , (median: 3.32, min-max: 2.60-6.57)

\begin{tabular}{|c|c|c|c|}
\hline & r & P-value & Lower 95\% Cl-upper 95\% Cl \\
\hline Age & 0.324 & 0.012 & $0.006-0.045$ \\
\hline HD duration & 0.334 & 0.008 & $0.001-0.004$ \\
\hline VD3 & & NS & \\
\hline ARB & & NS & \\
\hline SBP & 0.411 & 0.001 & $0.008-0.029$ \\
\hline DBP & 0.38 & 0.003 & $0.009-0.044$ \\
\hline $\mathrm{PCl}$ & & NS & \\
\hline CLI & & NS & \\
\hline DM & & NS & \\
\hline $\mathrm{Hb}$ & & NS & \\
\hline BUN & & NS & \\
\hline CRP & 0.28 & 0.025 & $0.075-1.124$ \\
\hline Alb & & NS & \\
\hline$\beta 2 M G$ & 0.277 & 0.033 & $0.005-0.111$ \\
\hline MMSE & & NS & \\
\hline
\end{tabular}

Abbreviations: Alb, albumin; $\beta 2 \mathrm{MG}, \beta 2$ microglobulin; ARB, angiotensin II receptor antagonist; BUN, blood urea nitrogen; $\mathrm{Cl}$, confidence interval; $\mathrm{CLI}$, critical limb ischemia; $\mathrm{Cr}$, creatinine; CRP, C-reactive protein; DBP, diastolic blood pressure; $\mathrm{Hb}$, hemoglobin; DM, diabetes mellitus; HD, hemodialysis; max, maximum; mini, minimum; MMSE, Mini Mental State Examination; NS, not significant; $\mathrm{PCl}$, percutaneous coronary intervention; rCBF, regional cerebral blood flow; SBP, systolic blood pressure; VD3, 1,25 $(\mathrm{OH}) 2$ vitamin D3.

There were positive correlations between a decrease in the severity of $\mathrm{rCBF}$ with a Z-score of more than 2 and age, HD duration, SBP, DBP, serum levels of CRP and $\beta 2 M G$

cognitive impairment. ${ }^{27}$ These reports may suggest that the decreased rCBF found in HD patients may be caused by vascular abnormalities leading to vascular dementia. However, we may not be able to discriminate between these two types of dementia (that is, vascular dementia or $\mathrm{AD}$ ).

Finally, regarding the pathophysiology, it is evident that numerous factors are involved in the decreased $\mathrm{rCBF}$, including traditional (diabetes mellitus, hypertension, etc.) and non-traditional risk factors, ${ }^{28}$ such as oxidative stress, thrombogenic factors, anemia, abnormal Ca/P metabolism, extracellular fluid overload, sleep apnea 
syndrome, inflammation (C-reactive protein), malnutrition and $\mathrm{NO} /$ endothelin imbalance. It has also been reported that increased viscosity and biochemical changes, such as urea reduction and blood alkalization, may have a role. ${ }^{29}$ Indeed, we also reported that the changes in blood viscosity and monocyte-platelet aggregates are closely associated with atherosclerosis in HD patients. ${ }^{30}$ During one session of HD treatment, rCBF decreased by $7 \pm 2.6 \%$, although the exact associated factors have not been reported. ${ }^{29}$ Hirakata et al. ${ }^{31}$ report that, based on positron emission tomography, oxygen metabolism decreases in relation with anemia, and vasodilatory capacity in brain vessels is limited. ${ }^{32}$ Kanai et al. ${ }^{33}$ have already reported important evidence. In their study, the hemispheric $\mathrm{rCBF}$ in the HD patients did not differ from the controls, but oxygen metabolism was depressed in the CKD patients before the dialysis treatment. Likewise, the fact that $\mathrm{rCBF}$ was inversely correlated with HD duration became evident. In their report, anemia, per se, might not be a major cause for impaired brain metabolism. Unfortunately, in our study a clear role for anemia could not be determined. Kanai et al. also reported that dialysis-related hypotension has a role in progressive frontal lobe atrophy in HD patients. ${ }^{34}$ Considering that blood pressure was chosen as an independent association factor for decreased rCBF, hypertension management might also be important. Variability in blood pressure in $\mathrm{HD}$ patients caused by the fluctuations of body fluids ${ }^{35}$ might contribute to decreased rCBF. However, we do not exclude an important contribution of hypotension in reduced brain perfusion and cognitive function. ${ }^{36}$

The present study has limitations. First, the small number of patients studied prevents definite conclusions. Further studies are clearly required to investigate the relationship between decreased $\mathrm{rCBF}$ and cognitive impairment. We must conduct a prospective cohort study. Therefore, the precise meaning of decreased rCBF remains unknown. Intradialytic hypotension, which could have a role in decreasing rCBF, cannot be investigated. However, our study is novel because it used SPECT for a quantitative comparison with age-matched non-dialysis healthy volunteers. We believe that the present study provides important information regarding whether medication can suppress the development of evident dementia or at least increase rCBF.

\section{CONCLUSION}

The results of the present study clearly show that $\mathrm{rCBF}$ was decreased in all the dialysis patients irrespective of the clinical symptoms or MMSE score. The relationship between decreased $\mathrm{rCBF}$ and cognitive impairment remains unknown. However, blood pressure control and the renin-angiotensin system appear to have important roles in decreasing rCBF.

1 Vermer SE, Prins ND, den Heijer T, Hofman A, Koudstaal PJ, Breteler MM. Silent brain infarcts and the risk of dementia and cognitive decline. New Engl J Med 2003; 348: 1215-1222.

2 Kobayashi S, Ikeda T, Moriya H, Ohtake T, Kumagai H. Asymptomatic cerebral lacunae in patients with chronic kidney disease. Am J Kidney Dis 2004; 44: 35-41.

3 Yamamoto Y, Ohara T, Nagakane Y, tanaka E, Morii F, Koizumi T, Akiguchi I. Chronic kidney disease, 24-h blood pressure and small vessel diseases are independently associated with cognitive impairment in lacunar infarct patients. Hepertens Res 2011; 34: 1276-1282

4 Teschan PE. Electroencephalographic and other neurophysiological abnormalities in uremia. Kidney Int Supp/ 1975; 2: 210-216.

5 Kurella Tamura M, Xie D, Yaffe K, Cohen DL, Teal V, Kasner SE, Messe SR, Sehgal AR, Kusek J, DeSalvo KB, Cornish-Zirker D, Cohan J, Seliger SL, Chertow GM, Go AS. Vascular risk factors and cognitive impairment in chronic kidney disease: The chronic renal insufficiency cohort (CRIC) study. Clin J Am Soc Nephrol 2011; 6: 248-256.

6 Khatri M, Nickolas T, Moon YP, Paik MC, Rundek T, Elkind MSV, Sacco RL, Wright CB. CKD associates with cognitive decline. J Am Soc Nephrol 2000; 20: 2427-2432.
7 Buchman AS, Tanne D, Boyle PA, Shah RC, Leurgans SE, Bennett DA. Kidney function is associated with the rate of cognitive decline in the elderly. Neurology 2009; 73 : 920-927.

8 Murray AM, Tupper DE, Knopman DS, Gilbertson DT, Pederson SL, Li S, Smith GE, Hochhalter AK, Collins AJ, Kane RL. Cognitive impairment in hemodialysis patients is common. Neurology 2006; 67: 216-223.

9 Kalirao P, Pederson S, Foley RN, Kolste A, Tupper D, Zaun D, Buot V, Murray AM. Cognitive impairment in peritoneal dialysis patients. Am J Kidney Dis 2011; 57: 612-620.

10 Jack X, de la Torre JC. Cardiovascular risk factors promote brain hypoperfusion leading to cognitive decline and dementia. Cardiovasc Psychiatry Neurol 2012; 2012. 367516.

11 Goldstein FC, Levey AI, Steenland NK. High blood pressure and cognitive decline in mild cognitive impairment. J Am Geriatr Soc 2013; 61: 67-73.

12 Fujisima M, Ibayashi S, Fujii K, Mori S. Cerebral blood flow and brain function in hypertension. Hepertens Res 1995; 18: 111-117.

13 Nakano S, Asada T, Matsuda H, Uno M, Takasaki M. Donepezil hydrochloride preserves regional cerebral blood flow in patients with Alzheimer's disease. J Nucl Med 2001; 42: 1441-1445.

14 Geaney DP, Soper N, Shepstone BJ, Cowen PJ. Effect of central cholinergic stimulation on regional cerebral blood flow in Alzheimer disease. Lancet 1990; 335: 1484-1487.

15 Wilkinson D, Doody R, Helme R, Taubman K, Mintzer J, Kertesz A, Pratt RD. Donepezil in vascular dementia. A randomized, placebo-controlled study. Neurology 2003; 61: 479-486.

16 Minoshima S, Frey KA, Koeppe RA, Foster NL, Kuhl DE. A diagnostic approach in Alzheimer's disease using three dimensional stereotactic surface projections of fluorine-18-FDG PET. J Nucl Med 1995; 36: 1238-1248.

17 Mizumura S, Kumita S, Cho K, Ishihara M, Nakajo H, Toba M, Kumazaki T. Development of quantitative analysis method for stereotactic brain image: Assessment of reduced accumulation in extent and severity using anatomical segmentation. Ann Nucl Med 2003; 17: 289-295.

18 Folstein MF, Folstein SE, McHugh PR. 'Mini-mental State': a practical method for grading the cognitive state of patients for the clinician. J Psychiat Res 1975; 12: 189-198.

19 Lezak MD, Howieson DB, Loring DW. Neuropsychological Assessment (4th edn). Oxford University Press, Oxford, 2004.

20 O'Bryant SE, Humphreys JD, Smith GE, Ivnik RJ, Graff-Radford NR, Petersen RC, Lucas JA. Detecting dementia with the mini-mental state examination in highly educated individuals. Arch Neurol 2008; 65: 963-967.

21 Minoshima S, Berger KL, Lee KS, Mintun MA. An automated method for rotational correction and centering of three-dimensional functional brain images. J Nuc Med 1992; 33: 1579-1585.

22 Talairach J, Tournoux P. Co-planar Stereotaxic Atlas of the Human Brain. Thieme Medical Publisher, New York, 1988.

23 Onishi H, Matsutomo N, Kai Y, Kangai Y, Amijima H, Yamaguchi T. Evaluation of a novel normal database with matched SPECT systems and optimal pre-filter parameters for 3D-SSP. Ann Nucl Med 2012; 26: 16-25.

24 Minoshima S, Foster NL, Kuhl DE. Posterior cingulate cortex in Alzheimer's disease. Lancet 1994; 344: 895.

25 Jagust W, Thisted R, Devous MD, Van Heertum R, Mayberg H, Jobst K, Smith AD, Borys N. SPECT perfusion imaging in the diagnosis of Alzheimer's disease. Neurology 2001; 256: 950-956.

26 Iwai M, Liu HW, Chen R, Ide A, Okamoto S, Hata R, Sakanaka M, Shinuchi T, Horiuchi M. Possible inhibition of focal cerebral ischemia by angiotensin II type 2 receptor stimulation. Circulation 2004; 110: 843-848.

27 Yagi S, Akaike M, Ise T, Ueda Y, Iwase T, Sata M. Renin-angiotensin-aldosterone system has a pivotal role in cognitive impairment. Hypertens Res 2013; 36: 753-758.

28 Sarnak MJ, Levey AS, Schoolwerth AC, Coresh J, Culleton B, Hamm LL, McCullough PA, Kasiske BL, Kelepouris E, Klag MJ, Parfrey P, Pfeffer P, Raij L, Spinosa DJ, Wilson PW. Kidney disease as a risk factor for development of cardiovascular disease. Circulation 2003; 108: 2154-2169.

29 Mildworf DGB, Rubinger D, Melamed E. The regional cerebral blood flow in patients under chronic hemodialysis treatment. J Cereb Blood Flow Metab 1987; 7: 659-661.

30 Kobayashi S, Okamoto K, Maesato K, Moriya H, Ohtake T. Important role of blood rheology in atherosclerosis of patients with hemodialysis. Hemodialy Int 2005; 9 . 268-274.

31 Hirakata $\mathrm{H}$, Yao H, Osato S, Ibayashi S, Onoyama K, Otsuka M, Ichiya Y, Kuwabara Y, Masuda Y, Fujishima M. CBF. and oxygen metabolism in hemodialysis patients: effects of anemia correction with recombinant human EPO. Am J Physiol 1992; 262: F737-F743.

32 Kuwabara Y, Sasaki M, Hirakata H, Koga H, Nakagawa M, Chen T, Kaneko K, Masuda K, Fujishima M. Cerebral blood flow and vasodilatory capacity in anemia secondary to chronic renal failure. Kidney Int 2002; 61: 564-569.

33 Kanai $H$, Hirakata $H$, Nakane H, Fujii K, Hirakata E, Ibayashi S, Kuwabara Y. Depressed cerebral oxygen metabolism in patients with chronic renal failure: a positron emission tomography study. Am J Kid Dis 2001; 38: s129-s133.

34 Mizumasa T, Hirakata H, Yoshimitsu T, Hirakata E, Kubo M, Kashiwagi M, Tanaka H, Kanai H. Fujimi S, lida M. Dialysis-related hypotension as a cause of progressive frontal lobe atrophy in chronic hemodialysis patients: a 3-year prospevtive study. Nephron Clin Pract 2004; 97: c23-c30.

35 Moriya H, Oka M, Maesato K, Mano T, Ikee R, Ohtake T, Kobayashi S. Weekly averaged blood pressure is more important than a single-point blood pressure measurement in the risk stratification of dialysis patients. Clin J Am Soc Nephrol 2008; 3: 416-422.

36 Duschek S, Schandry R. Reduced brain perfusion and cognitive performance due to constitutional hypotension. Clin Auton Res 2007; 17: 69-76. 